\title{
The Tunisian Tourism Business: What We Learn About The European Demand?
}

\author{
Jlassi Kamel, Tunisian Central Bank, Tunisia \\ Zied Ftiti, EDC Paris Business School, France \\ Hasna Chaibi, University of Tunis and University of El Manar, Tunisia
}

\begin{abstract}
People from European countries are traditionally the most important sources of tourism for Tunisia. The aim of this paper is to analysis the European tourism demand for Tunisia. we propose a vector autoregression error correction model. The following methodology allows us to analysis the dynamic of Tunisian tourism in both short-term and long-term. Our main results show that the real exchange rate is an important factor explaining long-term overnight stays. A currency depreciation of $10 \%$ will increase the number of nights spent by visitors by $12 \%$ in the long term, but will have the opposite effect in the short term. However, we show that tourism demand is inelastic to income, indicating the low-cost nature of Tunisian tourism.
\end{abstract}

Keywords: Cointegration; Error Correction Model; Tourism Demand; Exchange Rate; European Countries; Supply Factors; Classical Demand Factors

\section{INTRODUCTION}

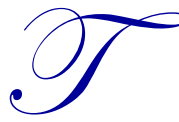

ourism activity is a source of income for many countries, especially for developing economies such as in Africa. Consequently, tourism plays an important economic role, as investing in this industry helps reduce the deficit of commercial balance and unemployment rates. Besides investigating the economic advantages of tourism, studies conducted by both tourism experts and academic researchers have analyzed tourism demand extensively. However, few of these studies have paid attention to tourism demand in African countries (Naudé and Saayman, 2005; Ouerfelli, 2008). As a result of the academic gap around this issue, the adequate tourism policies have not been implemented yet in countries whose growth is extremely dependent on the tourism industry (Christie and Crompton, 2001). For example, in the case of Tunisia, the tourism industry's income represents only 7\% of its gross domestic product (GDP) over the last decade (2000-2010).

The Tunisian tourism industry has shown sustained growth since the 2000s, despite its seasonality and its limited diversity (mainly resorts). However, given the large hotel infrastructure, stable political climate, and favorable economic conditions, tourism demand has not grown significantly compared to competing countries (Turkey, Egypt, and Morocco). The emergence of new types of cultural, leisure, golf, and health tourism (including thalassotherapy) and the improvement of the hotel infrastructure, all things being equal, should contribute to an increase in the tourism demand for Tunisia. Nevertheless, a great part of this demand is fulfilled by Tunisia's competing destinations (Turkey, Egypt, and Morocco). Although Tunisia benefits from an ideal combination of good climate and man-made factors (such as culture, heritage, or other factors resulting from human activity), that does not attract a high number of tourists. This problem has increased since the Arab Spring ${ }^{1}$ (January 14, 2011). Consequently, several policy actions have been undertaken in an attempt to boost tourism. We believe that these failures are attributed to the absence of academic research on the determinants of Tunisian tourist demand. The most significant published study on tourism in Tunisia rather explores the reciprocal relationship between growth and tourism (Ouerfelli, 2008). The question that arises at this point is how Tunisia could improve the competitiveness of its tourism industry by creating favorable conditions for the supply side. ${ }^{2}$

\footnotetext{
${ }^{1}$ A series of anti-government uprisings in various Arabic countries, beginning in Tunisia in January 2011.

${ }^{2}$ It should be noted that professionals in the Tunisian tourism industry already acclaim the exchange rate. 
The main purpose of this paper is to determine the causes of tourism decline in Tunisia by studying the determinants of tourism demand for this country. Literature proposes two approaches to identify the determinants of tourism demand, namely the supplier induced demand approach and the classical demand approach. Consequently, the variables involved in explaining tourism demand depend on which approach is followed. In this paper, we propose to study Tunisian tourism demand via a variable only recently mentioned in the literature, namely the number of nights spent by visitors. The variable is an indicator of the tourism intensity and subsequently of the tourism revenue. Further, it provides information about the offered accommodation capacity. This variable offers the advantage of combining the supplier induced demand approach and the classical demand approach. Contrary to most of the previous empirical approaches that did not consider the dynamic interactions between the short-term and long-term effects (Lathiras and Siriopoulos, 1998; Kulendran and Witt, 2001; Balaguer and Cantavella-Jorda, 2002; Dritsakis, 2004; Habibi and Abdul-Rahim, 2009), we propose a vector autoregression error correction model (VARECM) approach. This allows integration of the short-term and the long-term dynamics. Our main results show that the real exchange rate is an important factor explaining long-term overnight stays. A currency depreciation of $10 \%$ will increase the number of nights spent by visitors by $12 \%$ in the long term, but will have the opposite effect in the short term. However, we show that tourism demand is inelastic to income, indicating the low-cost nature of Tunisian tourism.

The remainder of the paper is organized as follows: The next section is devoted to related literature. Thereafter, the data and model specification are discussed. The results and discussion are presented in the section after that, and the last section concludes the paper.

\section{LITERATURE REVIEW}

Most of the studies on tourism in developed countries have been interested in determining the causality between tourism and economic growth. For developing countries, empirical research is concentrated on determining factors underlying tourism demand. A large number of studies published on tourism demand use several variables and different econometrical approaches. These studies include, among others, Kulendran and King (1997), Kulendran and Witt (2001), Smeral and Weber (2000), Tan et al. (2002), Song et al. (2003), Dritsakis (2004), Naudé and Saayman (2005), Chevillon and Timbeau (2006), Ouerfelli (2008), Abdul Rahim (2009), Belloumi (2010), and Tang (2011). According to these studies, the main used variables are the income of the country of destination (Munoz and Amaral, 2000; Thompson and Thompson, 2010), the number of visitors (Dritsakis, 2004; Chevillon and Timbeau, 2006; Tang, 2011) and the number of nights (Ouerfelli, 2008, Garin-Muňoz, 2007). However, as mentioned previously, the choice of variables depends on which of the two theoretical approaches - the supplier induced demand approach or the classical demand approach - is used as well as the income and price factors. According to the classical demand approach, the real GDP of the origin country and the exchange rate are the most important variables that explain tourism demand.

Different empirical methods are used for the two approaches mentioned above. One group of literature employs time series techniques by using the cointegration technique and the error correction model (ECM). Balaguer and Cantavella-Jorda (2002) use the cointegration approach to examine the relationship between tourism, the exchange rate, and growth in the Spanish market between 1975 and 1997. They find that tourism is cointegrated with these variables. Similarly, Dritsakis (2004) analyzes the long-term determinants of Greece's tourism demand to the German and British markets employing the cointegration technique and the ECM. He finds that the GDP of origin countries, the price index of tourist services, the cost of transport between Greece and the two other countries, and the exchange rate are the main determinants of tourism demand for Greece. Other studies such as Belloumi (2010) Chevillon and Timbeau (2006), Habibi and Abdul-Rahim (2009), and Lathiras and Siriopoulos (1998) use similar empirical methods to determine the real GDP per capita, the real exchange rate, and relative prices between countries of destination and competing countries in order to analyze tourism demand. Chevillon and Timbeau (2006) have used an ECM from 1980 to 2000 to explain tourism demand for France. By using certain variables, namely the GDP of origin countries, the real exchange rate, and the relative cost of tourism in the destination country, they find that the degradation of the tourism revenue is mainly due to the exchange rate effect. Tang (2011) uses the cointegration technique to study monthly data from January 1989 to May 2010 to explain the dynamics of tourists in Malaysia in terms of the real GDP and the real effective exchange rate. He indicates that there is a cointegration 
relationship between these variables. Tang (2011) proves that the short-term exchange rate and the real GDP affect the tourist numbers.

A second group of literature uses a panel data approach in order to explain tourist demand. Ibrahim (2011) uses panel data econometrics to analyze the determinants of Egypt's tourist demand during the period 1990 to 2008. He concludes that tourism in Egypt is very sensitive to relative prices with an elasticity of about -1.96 . The real exchange rate and GDP per capita elasticity are about -0.25 and 0.5 , respectively. Although the panel data analysis increases the degrees of freedom of the regression and reduces multicollinearity, the obtained results are highly sensitive to the presence of outliers' observations and unobservable heterogeneity. Other studies investigate factors relating to what the tourist destinations have to offer. Naudé and Saayman (2005) analyze variables such as accommodation capacity, communication infrastructure and marketing, as well as other factors such as political stability, travel cost, and health issues. They consider panel data for 43 African countries over the period 1996 to 2000. They find that political instability, development, tourism infrastructure, and marketing and information are the explanatory variables for tourism demand in these countries. However, price levels and travel costs have no significant explanatory power. Dupont (2006) uses other variables such as air supply capacity, represented by the number of airline companies who fly between France and Martinique, and promotional expenses incurred abroad, alongside other variables influencing demand. Using data from 1988 to 2002, he shows that the variables capturing the price effects explain tourism demand better than supply variables. Other econometric approaches have been proposed to provide robust explanations for tourism demand. Thompson and Thompson (2010) consider a program of utility function optimization for an international tourist who seeks to maximize total utilization under the constraint of source country income. The quantity of goods consumed at home and in the receiving country is thus maximized. These authors use annual data from 1976 to 2006 to analyze the tourism revenue in Greece. The quantity of goods consumed in the destination country is determinate by travel costs and the real exchange rate. It is highlighted that Greece's tourism demand is inelastic. The authors show that tourism price appreciations can increase tourism revenue. However, an increase in travel costs reduces the tourism revenue. Ouerfelli (2008) considers a model of transfer function and an autoregressive distributed lag specification highlighting the seasonality of tourism demand for Tunisia. He shows that the number of nights people stay, could be determined by prices, income, and supply.

All these studies do not consider the dynamic interaction between short-term and long-term consequences. In this paper, we suggest that a VAR-ECM approach would resolve the above-mentioned shortcoming of previous studies. This model allows integrating short-term dynamics and long-term consequences. In addition, it is better to use a variable that consider the conditions of supply and demand at the same time, i.e. the number of nights spent by the visitor.

\section{EMPIRICAL STRATEGY AND DATA}

\section{Data}

Tourists in Tunisia are mainly from European (60\%) and Maghreb (40\%) countries (Figure 1, appendix). Even though $60 \%$ of the tourists come from Europe and $40 \%$ from the Maghreb region, in terms of overnight stays, Europeans represent a share of $95 \%$ against the 5\% North Africans (Figure 2, appendix). Based on these statistics, we suggest that the analysis of tourism demand in terms of the number of visitors cannot provide robust interpretations. In this paper, we propose to study tourism demand for Tunisia via the number of nights spent by visitors. This serves a dual purpose: It indicates the intensity of tourism and subsequently the tourism revenue and provides us with information on the capacity of offered accommodation. Consequently, this variable should be pertinent in determining the determinant of tourism demand for Tunisia.

From the supply side, several factors seem to influence the potential tourist demand, such as the accommodation capacity, the quality of service, the image of Tunisia as a tourist destination... However, the seasonal pattern of Tunisian tourism (Ouerfelli, 2008) reduces the assumption that the supply factors are determining variables of tourism demand. For our analysis, we use the following variables: the tourists' spent nights, the real income per capita in the origin countries, and a dummy variable. 
- The number of tourists' spent nights (NTSN): This is the number of nights spent per tourist/visitor from the Euro zone.

- The real income per capita (RI) in the origin countries: This describes the countries' economic situations. It is measured by dividing the GDP of the origin country by both its population and its consumer prices index. An increase in the GDP of a country is likely to increase the number of spent nights by a visitor from that country, all things being equal. By using the real per capita income, we can control the effect of the population size and inflation on tourism demand. The data on GDP and population size in the Euro zone are taken from the World Development Indicators compiled by the World Bank.

- The real effective exchange rate (REER): This is obtained by adjusting the nominal exchange rate in terms of the inflation differential. It is calculated as follows:

$$
R E E R=\frac{N E R * p^{d}}{p^{f}}
$$

$N E R$ is the nominal exchange rate of the currency in terms of dinar, and $p^{d}$ and $p^{f}$ are the prices for domestic consumption and foreign price, respectively. Balassa (1973) discusses the impact of the real exchange rate relative to the nominal exchange rate. A real appreciation (an increase of REER) increases the tourism price and reduces the NTSN. However, the tourists' income increases if travel demand is inelastic. We expect a positive sign for this variable.

- $\quad$ Dummy: To take into account the dinar devaluation in 1986.

All data used in our study have an annual frequency and cover the period 1975 to 2010 . These data are from the brochure of financial statistics of the Central Bank of Tunisia. All variables are estimated in logarithmic form. Consequently, we will obtain the elasticity estimates of the explained variables. The expected signs are al $>0$, a2 $<0$.

\section{Empirical Strategy}

Based on previously cited literature such as Dritsakis (2004), Katircioglu (2010), and Tang (2011), we suggest that tourism demand for Tunisia is dependent on income, relative prices, REER, and a dummy variable. The specification adopted is based on a linear equation in logarithmic form. In our empirical specification, a dummy variable was introduced in order to take into account the dinar devaluation of 1986. It should be noted that there are other factors that influence tourism income, such as transport cost, air capabilities, promotional expenses incurred in foreign tourist arrivals (lagged by one year to capture the phenomenon of customer loyalty and the phenomenon of word of mouth marketing), and diversification of services offered. However, the uniqueness of Tunisia's tourism sector lies in the fact that this industry offers an oversupply, which, in fact, causes restrained demand. Therefore, our main objective is to determine the tourism demand determinants in order to propose an optimal supply allowing of Tunisian proposed. Currently, empirical studies increasingly use a combined approach of the cointegration technique and the ECM. The latter allows identifying the adjusted short-run mechanisms compatible with a model explaining the long-term ones (cointegration technique). To study the interaction between the tourism demand for Tunisia and the explanatory variables, we use a combined specification of the autoregressive model and an unvaried ECM estimated in a single step (Ericsson and Mckinnon, 2002). Economic analysis accords great significance to price elasticity and income elasticity in explaining the evolution of the tourism demand. The elasticity measures the variation level of tourism demand in the case of income and/or price increases or decreases. Both short-run and long-run indicate the impact of cyclical fluctuations on the pattern of variables. (ECM):

Therefore, our model takes the following form and will be estimated as a Vector error correction model

$$
\operatorname{NTSN}_{t}=\alpha_{0}+\alpha_{1} R I_{t}+\alpha_{2} R E E R_{t}+\operatorname{DUMMY}_{t}+\epsilon_{t}
$$


The variables presented in the equation (2) can be non-stationary times series in level and they can be integrated. For the last case, they can also be cointegrated if one or more linear combinations among them are stationary. Subsequently, there exist possibly a stable long-run linear equilibrium relationship among them. For instance, if Tunisian tourism demand is measured by nights per visitor and real income, and are not cointegrated, then the NTSN would hover above or below the income level in the long run. Granger (1986) argues that "[a] test for cointegration can thus be thought of as a pre-test to avoid 'spurious regression' situations" (p. 226). Furthermore, Engle, and Granger (1987) say that "it may not be so easy to test whether a set of variables are cointegrated before estimating a multivariate dynamic model" (p. 264). Cointegration and error correction models are closely related. Engle and Granger (1987) define error correction as when "a proportion of the disequilibrium from one period is corrected in the next period" (p. 254). An error correction model relates the change in one variable to past equilibrium errors.

If the hypothesis of a unit root is accepted, then a test for cointegration is performed. The hypothesis being tested is the null of non-cointegration against the alternative of cointegration, using Johansen's maximum likelihood method. A vector autoregression approach is used to model each variable (which is assumed to be jointly endogenous) as a function of all the lagged endogenous variables in the system. The method of Johansen (1991) related to the combined analysis of the VAR-ECM is used to separate the effects of short-term and long-term consequences. Thus, each variable is explained by its own lagged values and those of other variables. Harris (1995) shows that the cointegration test is validated even if the variables of different orders are integrated, since the unit root test is sensitive to sample size and statistical problems. Similarly, Enders (1994) notes that the Johansen test for cointegration could be done even when the variables of different orders are integrated. Tsai and Chen (2001) have argued that the Johansen cointegration test is a generalization of the augmented Dickey-Fuller (ADF) test. In addition, if the variables are cointegrated, the order of integration of the variables is less disturbing (Muscatelli and Hurn, 1992; Tang, 2010). Johansen (1988) considers a simple case where $Y_{t}$ is integrated of order one, in such a way that the first difference of $Y_{t}$ is stationary. If we suppose that vector $Y_{t}$ is defined by an unrestricted VAR system of order $(n \times 1), Y_{t}$ can present as follows:

$$
Y_{t}=\Gamma_{1} X_{t-1}+\Gamma_{2} X_{t-2}+\cdots+\Gamma_{k} X_{k-1}+\mu_{t}
$$

Where the $\Gamma_{i}=(n \times n)$ matrix of unknown parameters to be estimated for $i=1,2, \ldots, k . \mu_{t}$ is the independent and identically distributed $(n \times 1)$ vector of error terms, and $t$ is the observations number. In our case, $t=1975,1976, \ldots, 2010$. The specification (3) can re-parameterized in the error correction form as:

$$
(1-L) Y_{t}=\sum_{i=1}^{k-1} \Lambda_{i}(1-L) Y_{t-i}+\Gamma Y_{t-k}+\mu_{t}
$$

Where $L$ is the lag operator, and $(1-L) Y_{t}$ is subsequently stationary. We define $I$ as an identity matrix:

$$
\Lambda_{i}=\sum_{i=1}^{k-1} \Gamma_{i}-I \text { and } \Gamma=\sum_{\mathrm{j}=1}^{\mathrm{k}} \Gamma_{\mathrm{i}}-I
$$

The Johanson approach consists, per definition, of the matrix $\Gamma$ as the product of $\psi$ and $\varphi$, two ( $n \times$ $r$ )matrices, each of rank $r$, such that $\Gamma=\psi \varphi^{\prime}$, where $\psi$ contains ther cointegration vectors and $\varphi$ represents the weighting elements matrix. Hence, by supposing $\Delta=(1-L)$, the error correction model (4) can be written as follows:

$$
\Delta Y_{t}=\sum_{i=1}^{k-1} \Lambda_{i} \Delta Y_{t-i}+\left(\phi \psi^{\prime}\right) Y_{t-k}+\mu_{t}
$$

\section{Results and Discussions}

Stationary Analysis

In time series analysis, the dynamic convergence to equilibrium requires that the variables must be stationary. Otherwise, the error standard deviation will be underestimated (Enders, 2004) and the regression will be spurious (Granger and Newbold, 1974; Phillips, 1986). In literature on time series, different stationary tests are used 
and the most popular are the ADF (1979) test and the Perron (1989) test. The ADF test is applied to time series where their pattern did not have a structural break (change in constant or trend). However, the Perron test allows for considering the problems of autocorrelation of the errors and heteroscedasticity. It is based on the same principals as the ADF test, but considers the existence of a structural change in the data. We test the null hypothesis $H_{0}$, where a series has a unit root, against the alternative hypothesis, $H_{1}$, where a series does not have a unit root, with a level confidence of $1 \%$. At this level, both tests did not reject the unit root hypothesis at $1 \%$, except for the REER that remains stationary in the Perron test. The REER graph (Figure 3, appendix) confirms the existence of a trend shift in the series justifying the Perron test result. This trend shift in the REER is explained by the devaluation of dinars in 1986. Consequently, in our analysis we introduce a dummy variable to take into account this factor. In the first differentiation, both tests (the ADF and the Perron test) show that all variables are stationary. The following table (Table 1) presents the results of stationary tests:

Table 1. Stationary Tests Results ${ }^{3}$

\begin{tabular}{lccc}
\hline & Variables & ADF Test & PERRON TEST \\
\hline RI & $\mathrm{I}(1)+\mathrm{bt}+\mathrm{c}$ & $\mathrm{I}(1)+\mathrm{c}$ \\
REER & $\mathrm{I}(1)$ & $\mathrm{I}(0)$ \\
NTSN & $\mathrm{I}(1)$ & $\mathrm{I}(1)$ \\
\hline
\end{tabular}

Cointegration and Johanson Test Results

Most of the variables that were reported in the model (eq. 5), namely the NTSN, the RI, and the REER are integrated of order 1, I(1). Therefore, they can be cointegrated on a VAR model as specified in the previous section. We start our analysis by determining the optimal lag of the VAR system. We use the criteria of Akaike (AIC), Schwartz (SC) and Hannan Quinn (HQ) with a number of maximum lags equal to 2, which means we will lose two observations when the maximum order may be compatible with the economic intuition for this type of model. A large number of lags imply that it is likely that there is an omitted variable in the initial system. The determination of the optimal order of lags is done in the presence of a deterministic component in the data (constant and trend). The cointegration test is very sensitive to these two factors as stipulated by Abeysinghe and Tan (1999). We will choose the number of lags that minimizes information criteria: SC (p), AIC (p), and HQ (z). The AIC, SC and HQ statistics for different lags are illustrated in the following table:

Table 2. AIC, SC and HQ Statistics for Different Lags

\begin{tabular}{|c|c|c|c|}
\hline Lags & AIC & SC & HQ \\
\hline 0 & -7.24 & -7.02 & -7.17 \\
\hline 1 & $-18.28 *$ & $-16.94 *$ & $-17.82 *$ \\
\hline 2 & -18.06 & -15.59 & -17.22 \\
\hline
\end{tabular}

(*) Indicates the order of lags that minimize the AIC and SC criteria

These three criteria are consistent and lead to the choice of the same order of delay. The optimal lag is 1 , i.e., the VAR (1). The second step is to determine the number of cointegration relationships. To test the existence of a cointegration relationship, we apply the multivariate test of Johansen and Juselius (1990) that allows for the cointegrating vectors to be more rigorous. To test the rank of the cointegration, Johansen (1988) proposes two types of tests:

The trace test: $\left\{\begin{array}{l}H_{0}: \text { Rank of } \Gamma=r \\ H_{1}: \text { Rank of } \Gamma=n\end{array}\right.$

In this test, we will test the null hypothesis that there are $r$ cointegration relationships against the alternative hypothesis that states that there are $n(r<n)$ cointegration relationships.

${ }^{3}$ Note: I(1) indicates that a series is integrated with order $1 ; \mathrm{I}(1)+\mathrm{c}$ : indicates that a series is integrated with order 1 with drift; I(1) + bt: indicates that a series is integrated with order land witha linear trend; $I(1)+b t+c$ indicates that a series is integrated with order 1 , a linear trend and a constant; $\mathrm{I}(0)$ : indicates that a series is stationary. 
The maximum eigenvalue test: $\left\{\begin{array}{c}H_{0}: \text { Rank of } \Gamma=r \\ H_{1}: \text { Rank of } \Gamma=r+1\end{array}\right.$

In this test, we will test the null hypothesis that there are $r$ cointegrating relationships against the alternative hypothesis that states that there are $r+1$ cointegrating relationships. It should be noted that these tests do not have standard distributions and their values have been tabulated by Johansen and Juselius (1990) and later by OsterwaldLenum (1992).

Both tests are sensitive to the lags and can render conflicting results. Usually, we retain the test that shows a higher number of cointegration relationships, or that has a higher critical value.

In addition, the existence of a cointegration relationship means that there is a long-term relationship between the cointegrated variables. This does not imply a static equilibrium that is checked at every moment, but rather implies a restoring force allowing the convergence of the system to its long-term average, even in the presence of temporary deviations. This is consistent with a dynamic equilibrium. This force can be represented by the susceptibility of economic operators to respond to deviations with respect to an equilibrium position.

Table 3. Cointegration Tests

\begin{tabular}{|l|c|c|c|c|c|}
\hline Eigen value & $\mathbf{H}_{\mathbf{0}} \boldsymbol{r}=$ & Test $\boldsymbol{\lambda}$-Max & $\begin{array}{c}\text { Critical value } \\
\text { at 95\% }\end{array}$ & Trace Test & $\begin{array}{c}\text { Critical Value } \\
\text { at 95\% }\end{array}$ \\
\hline 0.529827 & 0 & 24.14897 & 22.29962 & 46.48791 & 35.19275 \\
\hline 0.387695 & 1 & 15.69681 & 15.89210 & 22.33895 & 20.26184 \\
\hline 0.187441 & 2 & 6.642132 & 9.164546 & 6.642132 & 9.164546 \\
\hline
\end{tabular}

Based on the tests presented in Table 3, we can see that there is one cointegration relationship of $5 \%$. When normalized for a unit coefficient of NTSN, the most appropriate cointegration regression of the long-run European tourist demand for Tunisia is given by VAR (1) as follows, when all variables are expressed in a logarithm function:

$$
\begin{aligned}
& \mathrm{NTSN}=0.05+0.24 \mathrm{RI}+1.18 \text { REER } \\
& \text { [1.06] [2.46] [2.01] }
\end{aligned}
$$

The coefficient estimates in the equilibrium relationship, which are estimated as long-run elasticities with respect to the NTSN, show that the exchange rate between European countries and Tunisia, and subsequently the income for European countries, are elastic. The results clearly indicate that the elasticity of the NTSN to exchange rate is greater than one. This provides strong evidence that the tourism demand for Tunisia is dependent on the exchange rate. In fact, a currency devaluation or depreciation of $10 \%$ results in a $12 \%$ increase in the NTSN in the long run. Therefore, the exchange rate becomes an important factor in deciding to spend more nights in a Tunisian hotel.

While the income elasticity is significant, it has a lower coefficient compared to the exchange rate. Consequently, the economic situation in the origin country (Europe) has a significant, but weak, impact on tourism demand for Tunisia. In other words, the economic situation does not have a greater influence on the Europeans' decision to visit and to spend time in Tunisia. The estimated value of less than one proves that European tourists consider Tunisia as a low-cost destination. 
ECM provides the short-term relationship. The estimated results are presented follows:

$$
\begin{aligned}
& \Delta \operatorname{NTSN}_{t}=-1,07\left(0.021816\left[\operatorname{DLN}(N T S N)_{t-1}\right]+0.130336\left[\operatorname{DLN}\left(\operatorname{NTSN}_{t-2}\right)\right]\right. \\
& {[-3.72] \quad[0.08] \quad[0.08]} \\
& -3.625495\left[D L N\left(R I_{t-1}\right)\right]-1.539895\left[D L N\left(R I_{t-2}\right)\right] \\
& {[-0.66] \quad[-1.56]} \\
& \left.-1.252078\left[D L N\left(R E E R_{t-1}\right)\right]-0.892454\left[D L N\left(R E E R_{t-2}\right)\right]-0.03260 D U M\right) \\
& {[-0.84][-1.3][-0.16]}
\end{aligned}
$$

The ECM specification shows that the long-term behavior of endogenous variables converged to their cointegraion relationships, while accommodating short-term dynamics. The estimated coefficients of ECM measure the speed of adjustment to restore equilibrium in the dynamic model. The restoring force of ECM is negative and significant. The Jarque-Bera test confirms the normality of residuals. Hence, the error correction model is validated. The ECM result (eq.7), traducing the short-term relationship, shows that the exchange rate continues to play an important role in the short run. From the results, the exchange rate elastiscities to NTSN are -1.25 for one year and -0.89 for two years, respectively. Therefore, a depreciation of $10 \%$ leads to a $12.5 \%$ decrease in the NTSN. Consequently, it has a negative effect on the European tourism demand for Tunisia.

These results have some important economic implications for Tunisian policymakers. They must be able to manage the Tunisian exchange rate risk to create the desired tourism demand suitable to meet the Tunisian tourism supply. In addition, policy makers must make the relevant changes to avoid that Tunisia is seen as a lower-cost destination.

\section{CONCLUSION}

In this paper, we propose to study tourism demand for Tunisia according to a new variable, namely, the number of nights spent by visitors. This method serves a dual purpose: The variable serves as an indicator of the intensity of tourism and subsequently the tourism revenue and provides information on the capacity of accommodation offered. Further, it offers the advantage of combing the supplier-induced demand approach and the classical demand approach. We find that the exchange rate and the income of origin country have a significant impact on the European tourism demand for Tunisia. We prove that the exchange rate has an important impact on decision making regarding overnight stays in both the short and long term. The income of origin country has a significant, but weaker effect than the exchange rate, which traduces the low-cost nature of Tunisian tourism. The economic implication of our results is that Tunisian policy makers have to manage the exchange rate risk well. They should also ensure that Tunisian monetary policy has some other objective in addition to price stability. Furthermore, they must undertake structural reforms in the tourism industry to ensure that tourists would no longer consider Tunisia as a lower-cost destination.

\section{REFERENCES}

Abeysinghe, T \& Tan K.B, (1999). Small Sample estimation of Cointegrating Vector: an Empirical Evaluation of Six Estimation Techniques. Applied Economics Letters, 6, 645-648.

Balaguer, L., Cantavella-Jorda, M. (2002). Tourism as a long-run economic growth factor: The Spanish case. Applied Economics, 34, 877-884.

Balassa, B. (1973) Just How Misleading are Official Exchange rate Conversions? A Comment. The Economic Journal, 83, 1258-1267.

Belloumi, M. (2010). The relationship between tourism receipts, real effective exchange rate and economic growth in Tunisia. International Journal of Tourism Research, 12 (5), 550-560.

Chevillon, G., Timbeau, X. (2006). L'impact de taux de change sur le tourisme en France. Revue de l'OFCE, 98(3), 167-181.

Christie, I.T., D.E. Crompton (2001). Tourism in Africa. Africa Region Working Paper, Series No. 12.The World Bank Washington DC. 
Dritsakis, N. (2004). Cointegration analysis of German and British tourism demand for Greece. Tourism Management, 25, 111-119.

Dickey, D. A., Fuller, W.A. (1979). Distribution of the estimators for auto-regressive time series with a unit root. Journal of the American Statistical Association, 74, 427- 431.

Dupont, L. (2006). Analyse des déterminants de la demande touristique aux Antilles Françaises. http://www.veilleinfotourisme.fr/analyse-des-determinants-de-la-demande-touristique-aux-antillesfrancaises-10596.kjsp

Enders (2004). Applied Econometric Time series, Applied Eco No Metric Time Series.

Engle, R. F., Granger, C. W. J. (1987). Co-integration end error correction: representation, estimation, and testing, Econometrica, 55, 251- 276.

Ericsson, N.R., Mckinnon, J. G. (2002). Distributions of error correction tests for cointegration, Econometrics Journal (2002), 5, 285-318.

Garin-Muňoz, T. (2007). German demand for Tourism in Spain. Tourism Management, 28, 12-22.

Granger, C. W. J. (1986). Developments in the study of cointegrated economic variables. Oxford Bulletin of Economics and Statistics, 48, 213-228.

Granger, C.W.J., Newbold, P. (1974). Spurious Regressions in Econometrics. Journal of Econometrics, 2, 111-120.

Habibi, F., Abdul-Rahim, K. (2009). A Bound Test Approach to Cointegration of Tourism Demand. American Journal of Applied Sciences, 6 (11), 1924-1931.

Harris, R. (1995). Using cointegration analysis in econometric modelling. Hemel Hempstead: PrenticeHall/Harvester Wheatsheaf.

Ibrahim M.A. (2011). The determinants of International Tourism Demand for Egypt: Panel Data Evidence. European Journal of Economics, Finance and Administrative Sciences, 30, 50-58.

Johansen, S. (1991). Estimation and hypothesis testing of cointegration vectors in Gaussian vector autoregressive models. Econometrica, 59, 1551-1580.

Johansen, S., Juselius, K. (1990). "Maximum Likelihood Estimation and Inference on Cointegration, with Applications to the Demand for Money. Oxford Bulletin of Economics and Statistics, 52,169-210.

Johansen S. (1988). Statistical Analysis of Cointegrating Vectors. Journal of Economic Dynamics and Control, 12 , 231-254.

Katircioglu, S. (2010). Testing the tourism-led growth hypothesis for Singapore - an empirical investigation from bounds test to cointegration and Granger causality tests. Tourism Economics, 16(4), 1095-1101.

Kulendran, N., King, M. L. (1997). Forecasting international tourist flows using error correction and time series models. International Journal of Forecasting, 13, 319-327.

Kulendran, N., Witt, S. F. (2001). Cointegration versus least squares regression. Annals of Tourism Research, 28, 291-311.

Lathiras, P., Siriopoulos, C. (1998). The Demand for Tourism to Greece: a Cointegration Approach. Tourism Economics, 4 (2), 171-185.

Munoz, T. G., Amaral, T.P. (2000). An econometric model for international tourism flows to Spain. Applied Economics Letters, 7(8), 525-529.

Muscatelli, V.A., HURN. S. (1992). Cointegration and Dynamic Time Series Models. Journal of Economic Surveys, $6,1-43$.

Naudé, W. A., Saayman, A. (2005). The determinants of tourist arrivals in Africa: a panel data regression analysis. Tourism Economics, 11(3), 365-391.

Ouerfelli, C. (2008), Cointegration analysis of quarterly European tourism demand in Tunisia, Tourism Management, vol. 29, pp. 127-137.

Osterwald-Lenum, M. (1992). A Note with Quantiles of the Asymptotic Distribution of the Maximum Likelihood Cointegration Rank Test Statistics. Oxford Bulletin of Economics and Statistics, 54, 461-472.

Perron, P. (1989). The Great Crash, the Oil Shock and the Unit Root Hypothesis, Econometrica, 57, $1361-1402$.

Phillips, P.C.B. (1986). Understanding Spurious Regressions in Econometrics. Journal of Econometrics 33, 311 340 .

Smeral, E., Weber, A. (2000). Forecasting international tourism trends to 2010. Annals of Tourism Research, 27(4), 982-1006.

Song, H., Witt, S. F., Jensen, T. C. (2003). Tourism forecasting: Accuracy of alternative econometric models. International Journal of Forecasting, 19, 123-141.

Tang, C. F. (2010). Tourism, real output and real effective exchange rate in Malaysia: a view from rolling sub- 
samples. MPRA Paper 29379, University Library of Munich, Germany.

Tang, C.F. (2011). Is the tourism-led growth hypothesis valid for Malaysia? A view from disaggregated tourism markets. International Journal of Tourism Research, 13(1), pp. 97-101.

Tan, Y. F., McCahon, C., Miller, J. (2002). Modelling tourist flows to Indonesia and Malaysia. Journal of Travel and Tourism Marketing, 12(1-2), 63-84.

Thompson, A., Thompson, H. (2010). The exchange rate, euro switch and tourism revenue in Greece. Tourism economics, 16(3), 773-780.

Tsai, C. H., Chen, C. W. (2011). The establishment of a rapid natural disaster risk assessment model for the tourism industry, Tourism Management, 32(1), 158-171.

Witt, S. F., Witt, C. (1995). Forecasting tourism demand: A review of empirical research. International Journal of Forecasting, 11(3), 447-475. 


\section{APPENDIX: Tunisian Tourism characteristics}

Figure 1. Distribution of arrivals tourist from the main transmitter regions

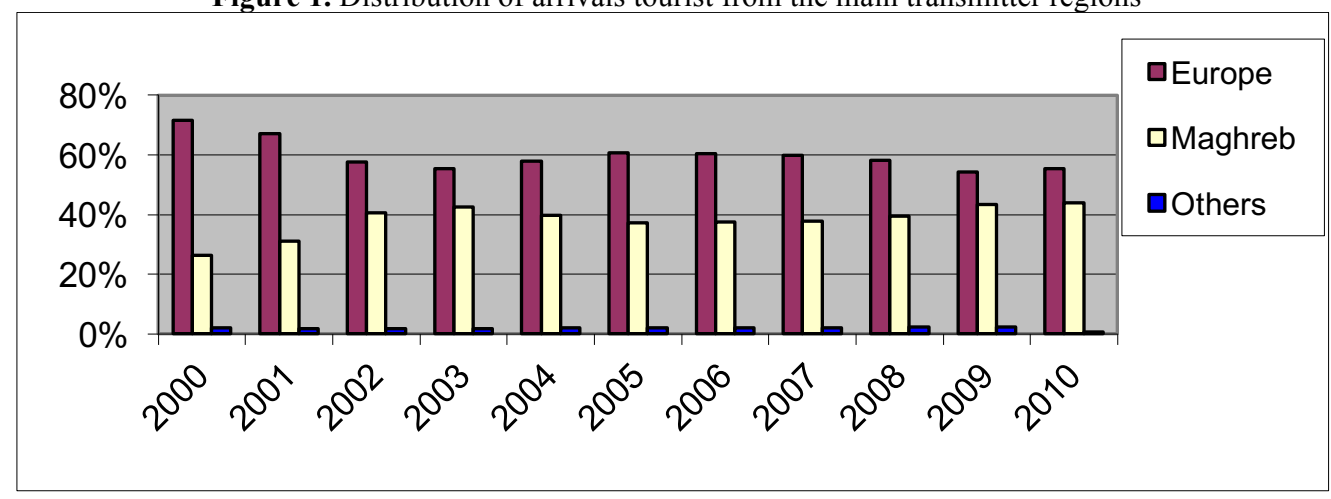

Figure 2. Distribution of nights by region

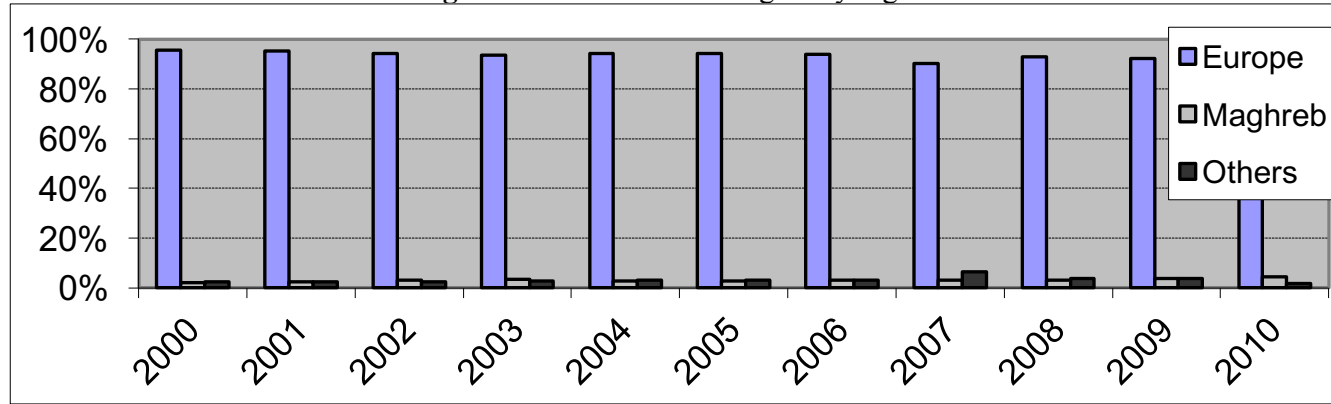

Figure 3. Evolution of the number of spent nights by visitor during the period 2000-2010

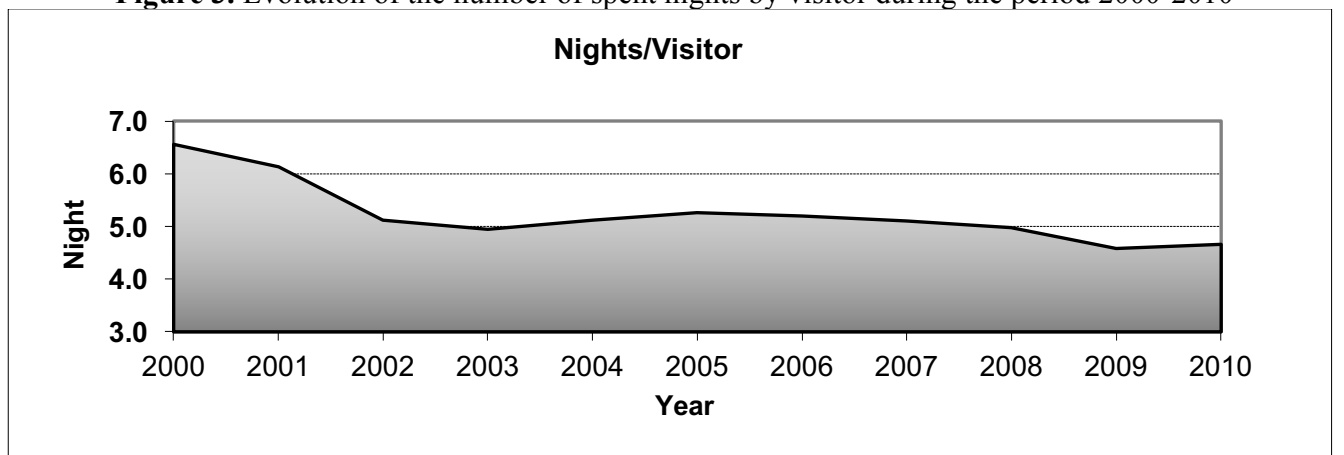




\section{NOTES}

